\title{
Carotid Paraganglioma. Experience of a Reference Center, UMAE Hospital De Especialidades Del Centro Médico Nacional “La Raza”, 964 Cases in 32 Years
}

\begin{abstract}
Héctor Bizueto-Rosas ${ }^{1}{ }^{*}$, Samuel Gutiérrez-Vogel${ }^{2}$, Ramiro Hernández-Salgado ${ }^{1+}$, Juan López-Silva², María Elizabeth Enríquez-Vega ${ }^{2}$, Alfonso Cossío-Zazueta ${ }^{2}$, Hugo Alonso Pérez-González ${ }^{3}$, Hilario Gómez-Valdez ${ }^{1}$, Carlos Martínez-López ${ }^{1}$, Roberto López-Rodríguez ${ }^{1+}$, Gonzalo Maldonado-Ibarguen ${ }^{1}$, Juan Ernesto Cruz-Castillo ${ }^{1}$, Oscar Andrés Rodríguez-Jiménez ${ }^{1}$, Ernesto Pacheco-Pittaluga ${ }^{1}$, Ely Guadalupe Moran-Reyes ${ }^{1}$, Gabriela Jimena Muñoz-Paredes ${ }^{1}$, Roberto Carlos Serrato-Auld ${ }^{1}$, Perla Elin Leyva-Rivera ${ }^{1}$, Armando Guzmán-Caballero ${ }^{4}$ and Carlos Daniel Gómez-Calvo ${ }^{5}$
\end{abstract}

\author{
${ }^{1}$ Department of Vascular Surgery and Angiology, "UMAE Hospital de Especialidades", Centro Médico Nacional "La Raza", Mexican Institute of Social \\ Security, Mexico \\ ${ }^{2}$ Chief of Vascular Surgery and Angiology, UMAE Hospital de Especialidades, Centro Médico Nacional "La Raza", Mexican Institute of Social Security, Mexico \\ ${ }^{3}$ Department of Vascular Surgery and Angiology, General Hospital, Institute of Security and Social Services of State Workers, Queretaro, Mexico \\ ${ }^{4}$ Resident of Vascular Surgery and Angiology, UMAE Hospital de Especialidades, Centro Médico Nacional "La Raza", Mexican Institute of Social Security, Mexico \\ ${ }^{5}$ Department of Vascular Surgery and Angiology, General Hospital, Institute of Public Health Services of Baja California State, Ensenada, Mexico \\ ${ }^{\dagger}$ Deceased authors
}

*Corresponding author: Héctor Bizueto-Rosas, Department of Vascular Surgery and Angiology, "UMAE Hospital de Especialidades", Centro Médico Nacional "La Raza”, Mexican Institute of Social Security, Mexico, E-mail: dr_bizueto_h@yahoo.com

Received: 20 Feb, 2020 | Accepted: 16 Mar, 2020 | Published: 20 Mar, 2020

Citation: Bizueto-Rosas H, Gutiérrez-Vogel S, Hernández-Salgado R, López-Silva J, Enríquez-Vega ME, et al. (2020) Carotid Paraganglioma. Experience of a Reference Center, UMAE Hospital De Especialidades Del Centro Médico Nacional "La Raza", 964 Cases in 32 Years. J Surg Open Access 6(3): dx.doi.org/10.16966/2470-0991.211

Copyright: (c) 2020 Bizueto-Rosas $\mathrm{H}$, et al. This is an open-access article distributed under the terms of the Creative Commons Attribution License, which permits unrestricted use, distribution, and reproduction in any medium, provided the original author and source are credited.

\author{
Abstract \\ Objective: Present our experience as a tertiary referral center in the surgical management of the carotid paraganglioma.
}

Introduction: Carotid paraganglioma is a slow-growing tumor, originated at the chemoreceptor cells of the carotid bulb and due to factors as chronic hypoxia, familiar history or female gender it can present hyperplasia. Most of these tumors are benign and asymptomatic which delays its diagnosis and treatment. Surgical excision is the gold standard treatment.

Methods: We performed an ambispective study from 1987 to 2019 of the patients with the diagnosis of carotid paraganglioma that underwent surgical excision in our center, using the Shamblin classification system to describe them.

Results: A total of 964 tumors were resected from patients of 21 to 82 years old, in 32 years, with an average of 30 procedures each year. $92 \%$ of the patients were female, Shamblin type I 7\%, type II 47\% and type III 46\%; bleeding went from 50 to $10,000 \mathrm{ml}$, with previous embolization in 8 cases, usage of stent-graft in 10 patients, 6 with external carotid artery ligation and only 1 patient with bypass using PTFE (Polytetrafluoroethylene) graft. Morbidity and mortality: cerebral vascular event in 3\%, bleeding $>2000 \mathrm{ml}$ in $11 \%$, nerve injury in $23 \%$, vascular injury in $25 \%$ and overall mortality $2 \%$.

Conclusion: In our center experience, surgical removal is the first treatment of choice; there is no benefit from using other therapies such as embolization, usage of stent-graft in the external carotid artery and only certain chosen patients could benefit from radiotherapy. Malignancy is less than $1 \%$, severe neurological complications in about $3 \%$. Genetic factor in our population, associated with the area height can be determinant.

Keywords: Carotid paraganglioma; Surgical excision

\section{Introduction}

Carotid body tumors are mostly benign, of slow-growth and originated at the chemoreceptor cells of the carotid bulb; they correspond to nearly half of the total paragangliomas [1,2]. According Glenner GG, et al. [3], the term paraganglioma is the most accurate to denominate these tumors [4].

Paragangliomas of the head and neck and the Carotid Body Tumor (CBT) are neuroendocrine tumors, they represent $0.6 \%$ of the head and neck total tumors and originate from the paraganglia of the autonomous nerve system [5]. They are associated with the parasympathetic nervous system so can be found from the skull base to the aortic arch [6]. Associated sudden death has been described [7] and can be locally invasive causing bone destruction and cranial nerve dysfunction [8]. About $10 \%$ are bilateral, although most are unilateral and sporadic [4]. Incidence of malignant tumors is below $10 \%$ but they can cause metastasis. Familiar presentation is usually around $10 \%$, in which cases the multi-locate presentation is of greater risk [9]. 
The incidence of these tumors is proportional to height due to a chronic hypoxia that stimulates carotid bulb hyperplasia [2] or due to chronic obstructive pulmonary disease. Due that most of the CBT are asymptomatic and of slow-growing rates (between 1 to $2 \mathrm{~mm}$ per year), diagnosis is belated $[10,11]$.

They are transmitted in an autosomal dominant manner through the gene and locus 11q23 [12] and the bilateral incidence is about 3 to $8 \%$ in sporadic cases and up to $33 \%$ in familiar cases [12]. In $79 \%$ of the head and neck paragangliomas, a mutation in the sub-unit $\mathrm{D}$ of the SDH gene is present, and it suggests the cause for multiple paragangliomas [13]. Female gender and age surrounding 60 years old are predominant [10].

The gene mutation SDHD is present in about $6-36 \%$ of the patients with head and neck tumors and up to $80 \%$ in familiar cases. The mutation P81L is used as a screening method for familiar paragangliomas in the USA [14].

According Shamblin WR, et al. [15], CBT can be classified in type I, II and III. Type I is the smallest tumor with very low adherence to the carotid arteries and with usually an easier surgical excision; type II is a tumor partially surrounding the carotid arteries and with firm adherence to the adventitia layer; and type III with an intimate, adherent relationship to the circumference of the carotid bifurcation [15]. Type III tumors are present in up to $25 \%$ of the cases, and in its surgical management vessel replacement is considered [15].

They are other suggested classifications in which the type III is divided in a) or b), according to Luna-Ortiz $\mathrm{K}$, et al. [16], considering a) as originally described or b) if vessel wall infiltration is present. Mayo clinic considers as type IIIa those that do not reach skull base and as type IIIb those reaching skull base and have no distal artery for considering suitable anastomosis (Zanaret and cols, 2000).

Another suggested classification states a difference regarding hemodynamic repercussion, for which a tumor between two and 5 centimeters without hemodynamic changes is considered type II, and those greater than 5 centimeters, skull base extension, wall infiltration, atheroma plaque or significant hemodynamic change is a type III (Maldonado-Diaz HO and cols, 2017).

\section{Material and Methods}

In a 32-year period, from 1987 to 2019 a total of 964 carotid body tumors were resected, from 24 to 65 cases per year with an average of 30 yearly. In this period a continuous record was kept, which was reviewed. Age went from 21 to 82 years old (mostly older patients whom specifically asked for surgical procedure). Diagnostic tools included clinical findings, Doppler ultrasound, CT scan and angiography; all discerned by the Shamblin classification.

\section{Results}

Of the total 964 carotid body tumors resected, one corresponded to a Castleman disease (giant lymph node hyperplasia) and other to an unusual neurofibromatous type of carotid body tumor. Histopathological report of the 964 tumors concluded as a "carotid paraganglioma, lymph hyperplasia", with malignancy confirmed in only one case; two other patients were associated with other malignant tumors. Mutation p81L of the SDHD gene (11q23) was found in $16 \%$ of the patients in heterozygous form [14].

Up to $92 \%$ of our patients were female with an average age of 55 years old. Regarding frequency as Shamblin type classification, type II were $47 \%$, type III were $46 \%$ (Figures 1 and 2 ) (Table 1 ).
Our average surgical time was 180 minutes (90 to 240 minutes) in those patients with Shamblin type III. We found no significant difference regarding bleeding using Cell Saver technology or bipolar electrocautery.

Bleeding was from 50 to $10,000 \mathrm{ml}$, with an incidence of major bleeding (considered as greater than $2000 \mathrm{ml}$ ) of 11\% (Figure 3).

Nerve injury incidence was of $23 \%$ (Figure 4), major vascular injury of $25 \%$ with an overall mortality of $2 \%$, consisting of deaths due to internal carotid artery thrombosis and cerebrovascular accident mostly.

Due to the volume of referred patients, previous embolization was elected in eight patients; one of them had a $10 \times 15 \times 15 \mathrm{~cm}$ tumor (Figure 5) that had several complications and died within the first day after embolization procedure.

Regarding management of carotid artery structures, in ten patients, a stent graft was placed from the common carotid artery to the internal

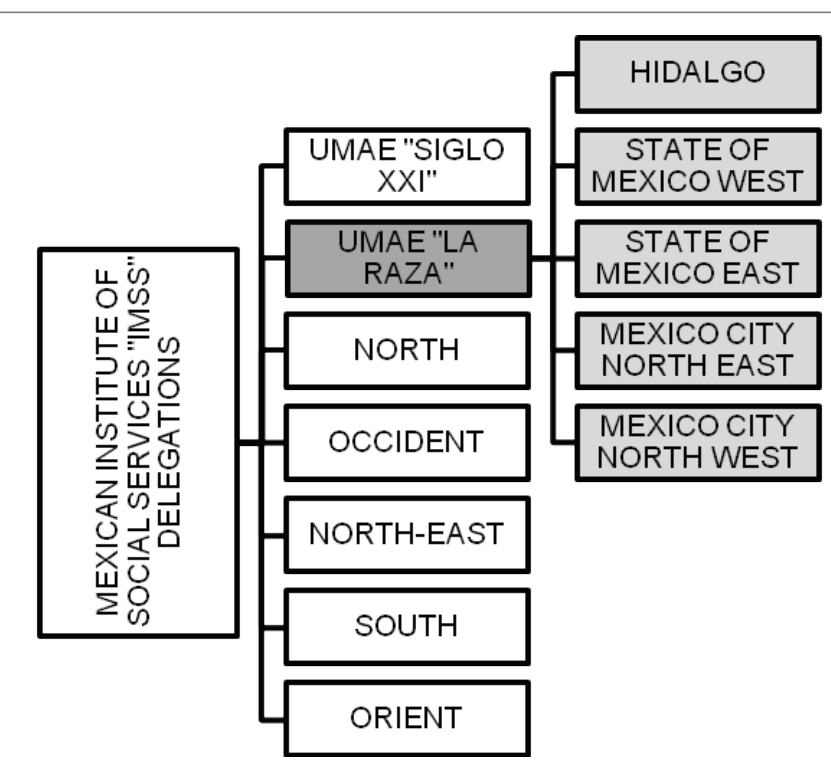

Figure 1: Above, "IMSS" delegations and reference center organigram with the regions of Mexico involved.

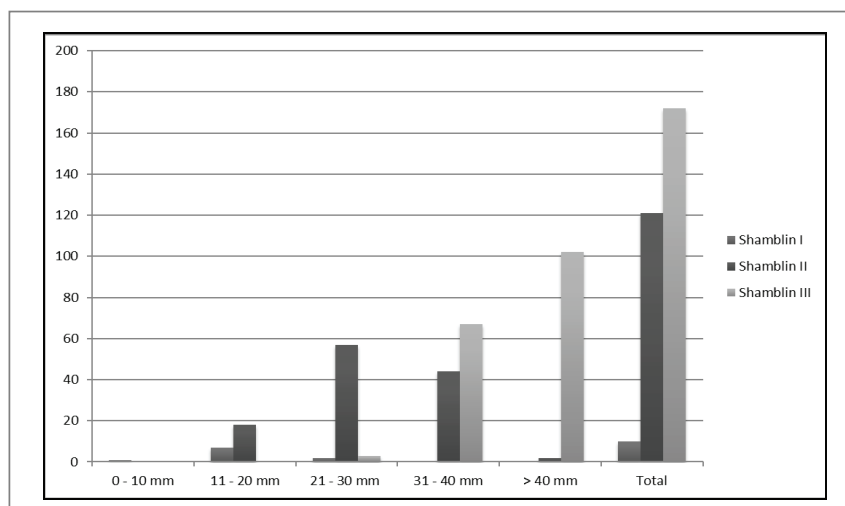

Figure 2: Patients with carotid body tumors distribution by size in millimeters and Shamblin classification, in the last five years. 
carotid artery to exclude external carotid artery and its branches to reduce blood supply and in other six patients, a double procedure took place, consisting of tumor resection and carotid dolichoectasia correction, and finally in three patients, a simultaneous carotid endarterectomy was performed.

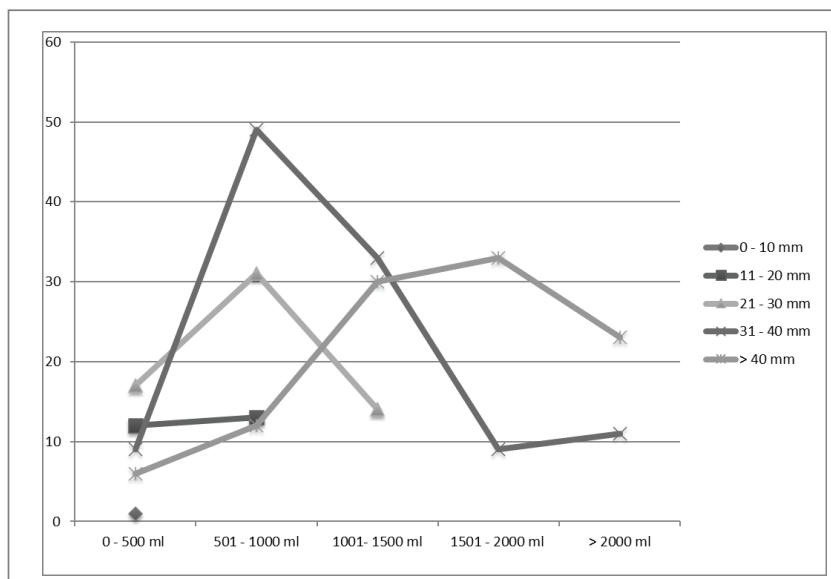

Figure 3: Surgical removal bleeding in the last five years, regarding size and blood loss in milliliters, considering patients in the last five years.

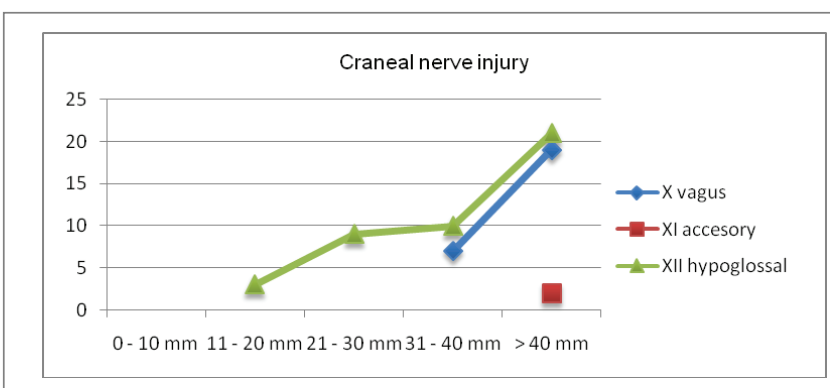

Figure 4: Number of patients and the association between size and cranial nerve injury, considering patients in the last five years.

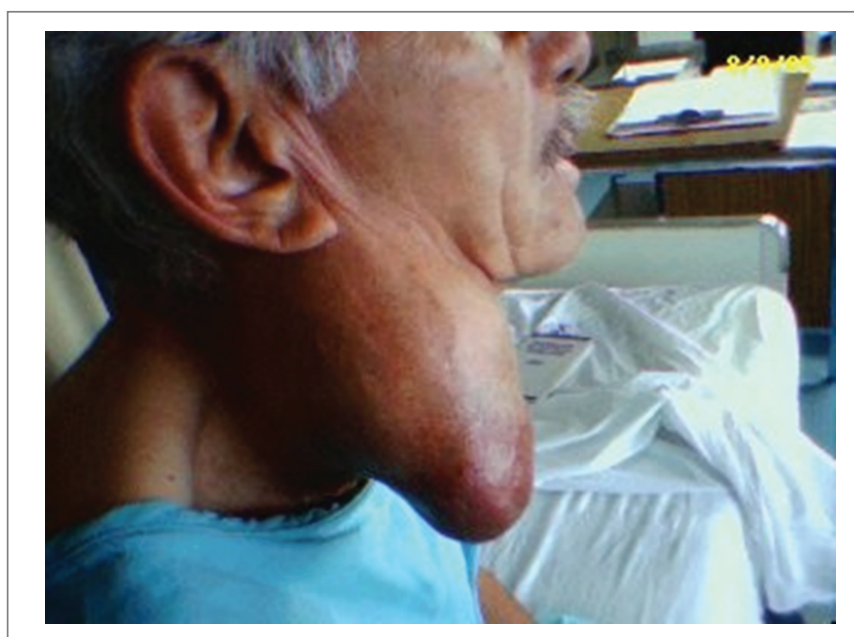

Figure 5: Male patient with Shamblin III right carotid body tumor of $10 \times 15 \times 15 \mathrm{~cm}$.
Of our records, six patients ended with external carotid artery closure, one patient required vascular reconstruction with PTFE (Polytetrafluoroethylene) graft, with an overall of 3\% cerebrovascular accidents.

Considering medical history $8 \%$ had familiar records and $20 \%$ were bilateral.

One patient had several syncope episodes that improved after tumor resection, and another patient had severe dysphagia associated with an $80 \%$ esophagic stenosis due to tumoral compression. In our medical records, only one patient has had a bilateral surgical removal of CBT with bilateral recidivist tumor after 5 years (Figure 6).

\section{Discussion}

\section{Diagnosis}

Clinical manifestations mostly involve a painless, slow-growing neck mass anterior to the sternocleidomastoid muscle, which is usually misdiagnosed as ganglia or airway related infections [9].

Doppler ultrasound is the most used diagnostic tool because of its availability and non-invasive approach; in experienced centers, it can provide anatomical detail, vascularization origin, size, surrounding vessel encapsulation and grade of atherosclerotic disease [17]. According to a comparison with CT o MR, ultrasound and color Doppler imaging failed to detect up to five of $60 \mathrm{CBT}$, scoring a sensitivity of $92 \%$ and specificity of $100 \%$ [18].

Regarding CT and MRI, the classic finding is described as the "lyre sign" due to the separation of both internal and external carotid arteries because of tumor growth in between. CT scan has a sensibility of 77 to $98 \%$ and a specificity of $92 \%$ and MRI has a $90-100 \%$ and $95 \%$ respectively [18]. In our center, a sub-analysis of our population, considering the geometrical findings of CT scan regarding internal carotid artery involvement with tumor showed a media of involvement of 220 degrees, being associated to a rate $30 \%$ of neurological injury during surgery and a most frequent classification of Shamblin III tumors; similar analysis are discussed by Kaddah RO, et al. [19].

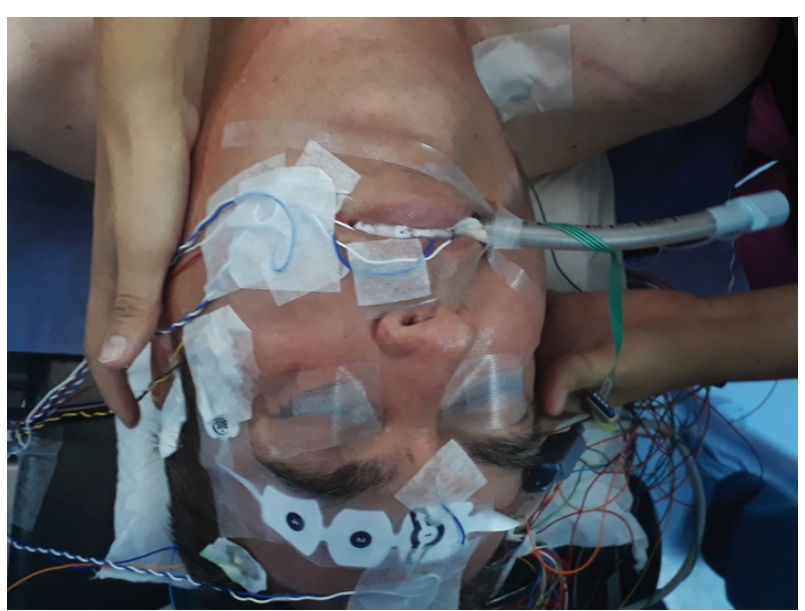

Figure 6: Anesthetic approach for carotid body tumor surgery with intraoperative cerebral monitorization and general anesthesia. 
Table 1: Below, the total population of those regions being 12,297,520 potential patients. All stated regions are above the 2000 meters of sea level. UMAE H CMN "High specialty medical unit, hospital, national medical center."

\begin{tabular}{|c|c|c|c|c|}
\hline Mexican States & State Population & Insurance Holders & $\begin{array}{c}\text { Population Allowed For } \\
\text { Medical Service }\end{array}$ & $\begin{array}{l}\text { Asigned to referal center u } \\
\text { mae h cmn "la raza" }\end{array}$ \\
\hline Hidalgo & 294,206 & 223,084 & 847,719 & 847,719 \\
\hline State of Mexico & $17,363,387$ & $1,559,744$ & $5,771,053$ & $5,771,053$ \\
\hline Mexico City & $8,811,266$ & $3,340,440$ & $11,357,496$ & $5,678,748$ \\
\hline Total & & & & $12,297,520$ \\
\hline
\end{tabular}

\section{Treatment}

Surgical removal is accepted as the best choice of treatment. Bleeding and nerve injury have an association with size and carotid vessels involvement, being directly associated with the Shamblin classification. In our center, those tumors considered as Shamblin III had an association of neurological injury up to $30 \%$, with predominance of the mandibular branch of the facial nerve, the glossopharyngeal nerve and the hypoglossal nerve in decrease order.

The usage of LigaSure TM by Medtronic is being used as an approach to reduce bleeding and surgical time, especially in large carotid body tumors, although carotid surgery is not in the manufacturer specifications, and nerve injury continues to be an important postoperative complication [16].

Embolization is an endovascular technique that aims to starve carotid body tumors of their blood supply, reduce the size, induce necrosis and in some cases, attempt an easier second-timed surgical approach; coils are the most used material.

Several have questioned the need to perform a previous embolization, considering risks, costs, nerve injury and a low significant impact [20].

Radiation therapy and stereotactic radiosurgery are proposed as other options for treatment, especially in high-risk patients, extensive tumor, advanced age or other specific conditions considering airway, bleeding risk, religion (example given, Jehovah's Witnesses and blood transfusion refusal) or no acceptance of surgery [21].

They are at least four genomic mutations that increase the risk of paraganglioma development; hereditary paraganglioma is usually diagnosed around 30 years of age [22,23].

The Succinate Dehydrogenase Enzyme (SDH) it is coded by the genes SDHB, SDHC and SDHD, and it play an important role on energy metabolism in mithocondrias. The enzyme performs as an oxygen sensor, and it has been described that hypoxia can trigger an SDHB mutation that has an important association with solid tumors [22].

The fact that $\mathrm{p} 81 \mathrm{~L}$ mutation of the SDHD gene is present in the Mexican population, in a greater proportion than in the American overall population, could explain our higher incidence, although, more data is required [14].

Regarding our center approach to treatment, data showed no significant benefit from other therapies such as embolization, stentgraft placement at the external carotid artery or radiotherapy, probably associated to a low number of cases managed by these therapies. The usage of LigaSure or Cell Saver also had no impact on the overall bleeding average.

We observe that in younger patients, with rapidly growing tumors and mostly in men, tumors more firmly adhere to the arteries and surrounding structures making the surgical approach more challenging, as well as surgery in those patients with thyroid impairment.

In terms of growth, a 1 to $2 \mathrm{~mm}$ yearly increase of volume is accepted as norm, but in our population, we observe that $20 \%$ of the patients refer a greater growth in a two to five years lapse [10,11].

The fact that Shamblin III tumors are as common as Shamblin II tumors it is probably due to the idiosyncrasy of our population (of do not ask for medical advice) and the great demand for medical services in our center. As for the association of Shamblin III tumors and the need for external carotid artery repair, we observe a dual cause, first due to the difficulty of the surgical removal and second due to overconfidence of our surgical team as being the center with the most cases.

In the last years, there is an increase in the Shamblin III type tumors.

In average our center provides 25 medical appointments daily, and in the last 19 years, there is an average of yearly surgical CBT removal or 45 patients, being a total of 461 from 1987 to 2007, 144 tumors removed from 2008 to 2013 and 357 from 2013 to 2019 [14,17].

Its combination with embolization is proposed as a first-choice treatment in some centers, although youngest patients, catecholamine secreting paragangliomas, or those rapidly progressing tumors may be more appropriate for open resection [21].

\section{Conclusion}

In our center experience, surgical removal is the first treatment of choice; there is no benefit from using other therapies such as embolization, usage of stent-graft in the external carotid artery and only certain chosen patients could benefit from radiotherapy. Malignancy is less than $1 \%$, severe neurological complications in about $3 \%$. Genetic factor in our population, associated with the area height can be determinant.

\section{Conflict of Interest}

Authors declare no conflict interest.

\section{References}

1. Lack EE, Cubilla AL, Woodruff JM, Farr HW (1977) Paragangliomas of the head and neck region: a clinical study of 69 patients. Cancer 39: 397-409.

2. Yáñez MR, Loyola B F, Cornejo FJ (2011) Tumor de cuerpo carotídeo. Rev Chilena de Cirugía 63: 513-518.

3. Glenner GG, Grimley PM (1974) Tumors of the Extra-adrenal Paraganglion System (including Chemoreceptors). In: Firminger HI (eds) Atlas of tumor pathology. Second series. U.S. Department of Defense, Armed Forces Institute of Pathology, The University of California 1-90. 
4. Salgado GS, Muentes DPM, Peralta KEE, Arias JLR (2009) Paragangliomas: métodos de imagen y correlación histopatológica. Anales de radiología México 4: 307-317.

5. Lee JH, Barich F, Karnell LH, Robinson RA, Zhen WK, et al. (2002) National Cancer Data Base report on malignant paragangliomas of the head and neck. Cancer 94: 730-737.

6. Baysal BE, Willet-Brozick JE, Lawrence EC, Drovdlic CM, Savul SA, et al. (2002) Prevalence of SDHB, SDHC, and SDHD germline mutations in clinic patients with head and neck paragangliomas. J Med Genet 39: 178-183.

7. van der Mey AG, Frijns JH, Cornelisse CJ, Brons EN, van Dulken $\mathrm{H}$, et al. (1992) Does intervention improve the natural course of glomus tumors? A series of 108 patients seen in a 32-year period. Ann Oto Rhinol Laryngol 101: 635-642.

8. Telischi FF, Bustillo A, Whiteman ML, Serafini AN, Reisberg MJ, et al. (2000) Octreotide scintigraphy for the detection of paragangliomas. Otolaryngol Head Neck Surg 122: 358-362.

9. Tamayo AP, Ruano PP, Muñoz HA (2009) Diagnóstico y control evolutivo de los paragangliomas de cabeza y cuello. Aportaciones de la medicina nuclear. Acta Otorrinolaringol Esp 60 Supl 1: 68-75.

10. Valencia DE, Clavijo RT, Hernández SA, Savigne GW (2016) Paragangliomas bilaterales del cuerpo carotideo. Rev Cubana Angiol Cir Vasc 17: 89-97.

11. Papaspyrou K, Mann WJ, Amedee RG (2009) Management of head and neck paragangliomas: review of 120 patients. Head Neck 31: 381-387.

12. Toranzo FMT, Colunga R, González VLG (2011) Paraganglioma de cuerpo carotídeo: reporte de un caso clínico con correlación familiar. Rev Esp Cir Oral Maxilofac 33: 79-83.

13. Antonello M, Piazza M, Menegolo M, Opocher G, Deriu GP, et al. (2008) Role of the genetic study in the management of carotid body tumor in paraganglioma syndrome. Eur J Vasc Endovasc Surg 36: 517-519.
14. Muñoz-Paredes GJ (2014) Presencia de mutación en el gen SDHD, en pacientes con tumor del cuerpo carotídeo, dentro de la población mexicana del Hospital de Especialidades CMN Antonio Fraga Mouret "La Raza" (tesis de grado). Instituto Mexicano del Seguro Social, Ciudad de México, México.

15. Shamblin WR, ReMine WH, Sheps SG, Harrison EG Jr (1971) Carotid body tumor (chemodectoma). Clinicopathologic analysis of ninety cases. Am J Surg 122: 732-739.

16. Luna-Ortiz K, Rascon-Ortiz M, Villavicencio-Valencia V, GranadosGarcía M, Herrera-Gómez A (2005) Carotid body tumors: review of a 20-year experience. Oral Oncol 41: 56-61.

17. Guzmán-Caballero A (2020) Asociación entre las dimensiones del tumor de cuerpo carotideo y las complicaciones postoperatorias. (tesis de grado). Instituto Mexicano del Seguro Social, Ciudad de México, México.

18. Dematte S, Di Sarra D, Schiavi F, Casadei A, Opocher G (2012) Role of ultrasound and color Doppler imaging in the detection of carotid paragangliomas. J Ultrasound 15: 158-163.

19. Randa OK, Magdy H, Usama L (2011) Impact of geometric concepts in Multislice CT angiography and MRI on surgical outcome of carotid body tumor. Egyp J Radiology Nuclear Med 42: 373-380.

20. Cobb AN, Barkat A, Daungjaiboon W, Halandras P, Crisostomo P, et al. (2018) Carotid Body Tumor Resection: Just as Safe without Preoperative Embolization. Ann Vasc Surg 46: 54-59.

21. Lieberson RE, Adler JR, Soltys SG, Choi C, Gibbs IC, et al. (2012) Stereotactic radiosurgery as the primary treatment for new and recurrent paragangliomas: is open surgical resection still the treatment of choice? World Neurosurg 77: 745-761.

22. Cerecer-Gil NY, Figuera LE, Llamas FJ, Lara M, Escamilla JG, et al. (2010) Mutation of SDHB is a Cause of Hypoxia-Related HighAltitude Paraganglioma. Clin Cancer Res 16: 4148-4158.

23. Instituto Valenciano de microbiología (IVAMI) Pruebas genéticas en paragangliomas. 